\title{
ESTRESSE SALINO ASSOCIADO À APLICAÇÃO EXÓGENA DE ESPERMIDINA NO ACÚMULO DE GLICINA BETAÍNA EM GUANDU $\left(^{1}\right)$
}

\author{
MOACIR VINÍCIUS PEREIRA DESTRO $\left(2^{*}\right)$; DURVALINA MARIA MATHIAS DOS SANTOS $\left({ }^{3}\right)$; \\ VANESSA CRISTIANE VOLLET $\left({ }^{4}\right)$; ADÃO MARIN $\left({ }^{5}\right)$; DAVID ARIOVALDO BANZATTO $\left({ }^{6}\right)$
}

\begin{abstract}
RESUMO
O objetivo do presente trabalho foi verificar o efeito do estresse salino associado à aplicação exógena de espermidina (Spd) nos genótipos de guandu, IAC Fava Larga e Caqui, no acúmulo de glicina betaína (GB), visando propor a sua utilização como marcador bioquímico-fisiológico à salinidade. O experimento foi instalado na Unesp, Faculdade de Ciências Agrárias e Veterinárias, em Jaboticabal (SP), no período de outubro a novembro de 2005, conduzido em sala de crescimento, com irradiância de $190 \mu \mathrm{mol} \mathrm{m}^{-2} \mathrm{~s}^{-1}$, fotoperíodo de 12 horas, temperatura de $25^{\circ} \mathrm{C}$ e U.R. de $40 \%$. A semeadura foi realizada em areia estéril, com adequado suprimento hídrico. Após 10 dias, as plântulas foram transferidas para solução nutritiva por 20 dias para aclimatação. A seguir, as plântulas foram alocadas nos tratamentos, sendo utilizado o delineamento experimental em blocos casualizados em esquema fatorial $2 \times 2 \times 4$ com os fatores genótipos (IAC Fava Larga e Caqui), Spd (0,0 e 0,5 mM) e estresse salino (0, 20,60 e $80 \mathrm{mM} \mathrm{de} \mathrm{NaCl})$. Após 20 dias sob estresse, foram determinados os teores de GB. Pelos resultados obtidos, a GB pode ser indicada como um marcador bioquímico-fisiológico do estresse salino para o 'IAC Fava Larga'.
\end{abstract}

Palavras-chave: salinidade, poliamina, osmólito compatível, betaína, Cajanus cajan.

(1) Recebido para publicação em 30 de outubro de 2006 e aceito em 29 de fevereiro de 2008.

$\left({ }^{2}\right)$ Mestrando pelo Programa de Pós Graduação em Agronomia na área de Genética e Melhoramento de Plantas, Faculdade de Ciências Agrárias e Veterinárias, FCAV/UNESP, Jaboticabal (SP). E-mail: mvpdestro@yahoo.com.br $\left(^{*}\right)$ Autor correspondente. Bolsista CAPES.

$\left({ }^{3}\right)$ Departamento de Biologia Aplicada à Agropecuária (DBAA), Laboratório de Fisiologia Vegetal, FCAV/UNESP, Rod. Paulo Donato Castellane, s/n. ${ }^{\circ}, 14884-900$ Jaboticabal (SP). E-mail: dumaria@fcav.unesp.br

$\left({ }^{4}\right)$ Mestranda pelo Programa de Pós Graduação em Agronomia na área de Genética e Melhoramento de Plantas. E-mail: vanessavollet@yahoo.com.br

$\left({ }^{5}\right)$ Doutorando pelo Programa de Pós Graduação em Agronomia na área de Produção Vegetal. Bolsista do CNPq. E-mail: admarin@fcav.unesp.br

$\left({ }^{6}\right)$ Departamento de Ciências Exatas, FCAV/UNESP, Jaboticabal (SP). E-mail: banzatto@netsite.com.br 


\title{
ABSTRACT \\ SALT STRESS ASSOCIATED TO EXOGENOUS SPERMIDINE APPLICATION ON THE ACCUMULATION OF GLYCINE BETAINE IN PIGEONPEA
}

\begin{abstract}
This study was undertaken to evaluate the effect of salt stress associated to exogenous spermidine (Spd) application on the accumulation of glycine betaine in the pigeonpea genotypes IAC Fava Larga and Caqui. The use of this compatible osmolyte as a biochemical-physiological indicator of salinity was also evaluated. The experiment was carried out at Unesp, Faculdade de Ciências Agrárias e Veterinárias, in Jaboticabal (SP), from October to November 2005, in a grow room with irradiance of $190 \mu \mathrm{mol} \mathrm{m}^{-2} \mathrm{~s}^{-1}$, photoperiod of 12 hours, temperature set to $25{ }^{\circ} \mathrm{C}$ and the $\mathrm{RH}$ to $40 \%$. Seeds were sowed in sterile sand with adequate water supply. After 10 days, seedlings were transferred to nutritive solution during 20 days for acclimation. The experiment was then arranged in randomized block design in a $2 \times 2 \times 4$ factorial, corresponding to the genotypes (IAC Fava Larga and Caqui), Spd rates (control and $0.5 \mathrm{mM}$ ) and salt stress $(0,20,60$ and $80 \mathrm{mM} \mathrm{NaCl})$. The levels of glycine betaine were determined after 20 days under stress. Our results show that glycine betaine can be used as a biochemical-physiological marker of salt stress in the 'IAC Fava Larga'.
\end{abstract}

Key words: salinity, polyamines, compatible osmolyte, betaine, Cajanus cajan.

\section{Introdução}

A salinidade dos solos é considerada um dos principais fatores abióticos responsável pelo estresse nas plantas, causando danos no metabolismo vegetal, reduzindo drasticamente a produtividade agrícola e provocando efeitos deletérios em muitos processos fisiológicos (MunNs, 2002). No mundo, estima-se que, cerca de 800 milhões de ha são salinizados, correspondendo a mais de $6 \%$ do total dos solos (MunNs, 2005). No Brasil, cerca de 4 milhões de ha de terras são afetadas por sais, as quais proporcionam baixas produtividades agrícolas ou, mesmo, estão excluídas do sistema produtivo (SzABOLCS, 1989).

O guandu (Cajanus cajan (L.) Millsp), leguminosa forrageira, é uma das principais culturas nos trópicos e subtrópicos, utilizada na forma de grãos, forragem ou adubo verde. Para o produtor rural, o guandu proporciona baixo custo de produção que se reflete diretamente no lucro da atividade pecuária e melhoria na fertilidade do solo, decorrentes da habilidade que esta forrageira representa para a fixação simbiótica de nitrogênio no solo (NENE et al., 1990). No Brasil, a principal utilização do guandu é na forragicultura, pois devido ao elevado potencial de produção de forragem e alto valor nutritivo é um excelente suplemento protéico para ruminantes, além de ser utilizado sob a forma de grãos ou farinha para aves e suínos (Costa et al., 2001).

Os vegetais, sob estresses ambientais, utilizam-se mecanismos complexos que contribuem para tolerar curtos períodos sob tais condições adversas. Dentre esses mecanismos, destaca-se o acúmulo substâncias denominadas "osmólitos compatíveis", que atuam na proteção de macromoléculas e na manutenção do turgor celular, preservando a integridade das células para as atividades vitais de crescimento e desenvolvimento vegetal (TAIZ e ZeIGER, 2004), principalmente, em condições de estresse salino (MunNs, 2006). Dentre tais substâncias inclui-se a amina quaternária glicina betaína $(N, N, N$-trimetilglicina), molécula anfótera, bipolar, com a propriedade de interagir com macromoléculas hidrofílicas e hidrofóbicas, enzimas e complexos protéicos, além de ser extremamente solúvel em água. Esta substância estabiliza as estruturas e atividades de enzimas e complexos protéicos, mantendo a integridade de membranas sob os efeitos deletérios da salinidade (SАкамото e Murata, 2002).

As poliaminas estão envolvidas em muitos mecanismos fisiológicos, participando direta ou indiretamente de várias vias metabólicas essenciais para o funcionamento celular e respostas aos diferentes estresses ambientais (MARTin-TANGUY, 2001). Em geral, observa-se, em plantas expostas ao estresse salino, aumento significativo na síntese de poliaminas, indicando possível defesa do vegetal sob condições adversas (TESTER e DAVENPORT, 2003). Ainda, quando aplicadas exogenamente na planta, as poliaminas podem causar acentuada redução dos efeitos deletérios do estresse salino (MARTIN-TANGUY, 2001).

Deste modo, verificou-se o efeito do estresse salino associado à aplicação exógena de espermidina (Spd) nos genótipos de guandu, IAC Fava Larga e Caqui, mediante a quantificação de glicina betaína (GB), tendo em vista a utilização desta substância como marcador bioquímico-fisiológico à salinidade.

O experimento foi realizado na UNESP Universidade Estadual Paulista, Faculdade de Ciências Agrárias e Veterinárias (FCAV), Departamento de Biologia Aplicada à Agropecuária (DBAA), Campus de Jaboticabal (SP), sendo 
desenvolvido no laboratório e na sala de crescimento, no período de outubro a novembro de 2005.

Para a obtenção das plântulas de guandu, as sementes dos genótipos IAC Fava Larga (G1) e Caqui (G2) foram semeadas em quatro bandejas de plástico contendo areia lavada e esterilizada, de acordo com VINCENT (1970). O experimento foi desenvolvido em sala de crescimento sob luminária com irradiância de $190 \mu \mathrm{mol} \mathrm{m}^{-2} \mathrm{~s}^{-1}$, fotoperíodo controlado de 12 horas, temperatura de $25^{\circ} \mathrm{C} \pm 2{ }^{\circ} \mathrm{C}$ (ar condicionado, 10.000 BTUs) e umidade relativa média de $40 \%$. Foram realizadas regas diárias para evitar qualquer carência hídrica.

Após 10 dias da semeadura, as plântulas de ambos os genótipos foram aclimatadas à solução nutritiva de Hoagland e Arnon (FERRI et al., 1974), sendo transferidas para frascos de vidro tipo SNAP CAP, com capacidade de $190 \mathrm{~mL}$, os quais foram previamente revestidos com papel alumínio para impedir o crescimento de algas na solução nutritiva. Para a aclimatação das plântulas foi utilizada solução nutritiva $50 \%$ (1/2 força) por cinco dias e em $100 \%$ (1/1 força) por mais 15 dias, totalizando 20 dias de aclimatação. Após este período as plântulas, com a idade de 30 dias após a semeadura (DAS), foram submetidas, simultaneamente, aos níveis de estresse salino com e sem adição de Spd.

Para verificar os efeitos de genótipos e estresse salino isento de $0,5 \mathrm{mM}$ de $\mathrm{Spd}$, as plântulas foram transferidas para solução nutritiva de Hoagland e Arnon 1/1 força com diferentes níveis de estresse salino, $0 ; 20 ; 60$ e $80 \mathrm{mM}$ de cloreto de sódio $(\mathrm{NaCl})$, de acordo com Gonela (1999).

$\mathrm{O}$ pH da solução nutritiva foi monitorado por peagômetro portátil Modelo PH206, sendo mantido em 6,1 $\pm 0,1$ utilizando-se solução de $\mathrm{HCl} 0,1 \mathrm{~N}$ ou $\mathrm{NaOH}$ $0,1 \mathrm{~N}$. Também, foi verificado os valores de condutividade elétrica (C.E.), utilizando-se condutivímetro portátil Modelo CD 4303, visando verificar a variação da concentração de $\mathrm{NaCl}$ na solução nutritiva.

Para verificar os efeitos de genótipos e estresse salino com adição de $0,5 \mathrm{mM}$ de $\mathrm{Spd}$, as plântulas foram aclimatadas, utilizando-se o mesmo procedimento acima citado. Assim, após 20 dias de aclimatação, as plântulas com 30 DAS, foram colocadas em solução nutritiva de Hoagland e Arnon $1 / 1$ força com os diferentes níveis de estresse salino, 0; 20; 60 e $80 \mathrm{mM}$ de $\mathrm{NaCl}$, com adição de $0,5 \mathrm{mM}$ da poliamina (Spd), Marca Spermidine Free Base Molecular Biology SIGMA S-0266.

$\mathrm{O}$ pH da solução nutritiva e a condutividade elétrica também foram monitorados, conforme a metodologia citada.
O delineamento experimental utilizado foi em blocos casualizados, no esquema fatorial $2 \times 2 \times 4$, com os fatores genótipos $\left(\mathrm{G}_{1}\right.$ e $\left.\mathrm{G}_{2}\right)$, concentrações de espermidina $\left(\operatorname{Spd}_{1}\right.$ e $\left.\mathrm{Spd}_{2}\right)$ e níveis de estresse salino $\left(E S_{1}, E_{2}, E S_{3}\right.$ e $\left.E S_{4}\right)$. Foram realizadas cinco repetições, por tratamento.

Após 20 dias, realizou-se a quantificação de GB em plântulas sob estresse salino isento de Spd e sob estresse salino com adição de $0,5 \mathrm{mM}$ de Spd, segundo método de Grieve e Grattan (1983).

Para a análise dos resultados, empregou-se o tratamento estatístico das características individuais através da análise de variância pelo teste $F$, utilizando-se do teste de Tukey para a comparação entre médias dos fatores qualitativos, genótipos e espermidina ( $\mathrm{G}$ e Spd). A análise da regressão polinomial foi utilizada para o desdobramento dos graus de liberdade do fator quantitativo, estresse salino (ES), de acordo com BanzatTo e KRONKa (2006).

$\mathrm{Na}$ análise dos resultados do acúmulo de GB, verificou-se que houve diferença significativa entre os genótipos, observando-se em 'Caqui' maior quantidade de GB que no 'IAC Fava Larga'. Também, foi observado que a adição exógena de Spd reduziu, significativamente, os teores de GB em ambos os genótipos de guandu (Tabela 1).

Pela análise de variância, houve efeito significativo do acúmulo de GB na interação tripla, G x Spd x ES (Tabela 1). Pelo estudo da regressão polinomial, verificaram-se, no genótipo IAC Fava Larga sob estresse salino e Spd $(0,0 \mathrm{mM}$ e $0,5 \mathrm{mM})$, regressões quadráticas, enquanto em 'Caqui' observaram-se regressões cúbicas (Figura 1).

Na comparação do tratamento isento de Spd $(0,0$ $\mathrm{mM})$, verificou-se que no genótipo Caqui a partir de 12,43 $\mathrm{mM}$ de $\mathrm{NaCl}$ ocorreu acúmulo de GB $\left(35,54 \mu \mathrm{mol} \mathrm{g}{ }^{-1}\right.$ massa seca) atingindo o máximo $\left(66,66 \mu \mathrm{mol} \mathrm{g}^{-1}\right.$ massa seca) em 65,89 mM de NaCl. Para 'IAC Fava Larga', somente, ocorreu acúmulo de GB $\left(29,37 \mu \mathrm{mol} \mathrm{g}^{-1}\right.$ massa seca) a partir de 31,47 mM de $\mathrm{NaCl}$ (Figura 1).

Verifica-se que houve acúmulo de GB à medida que ocorreu o aumento da salinidade no substrato. Porém, no genótipo Caqui a partir de $65,89 \mathrm{mM}$ de $\mathrm{NaCl}$ ocorreu significativo declínio da quantidade de GB, observando-se nas plântulas deste genótipo ajustamento osmótico, através do acúmulo de GB, apenas sob estresse salino entre 10 a $70 \mathrm{mM}$ de $\mathrm{NaCl}$. Os resultados observados para o genótipo Caqui podem indicar que houve aumento de $\mathrm{Na}^{+}$e do $\mathrm{Cl}^{-}$no citoplasma, pelo fato de ter excedido a capacidade deste genótipo a compartimentalizar os sais no vacúolo e, conseqüentemente, causar inibição das atividades enzimáticas (MunNs et al., 2006), conduzindo a redução da biossíntese de GB a partir de $65,89 \mathrm{mM}$ de $\mathrm{NaCl}$. 
Tabela 1. Análise de variância e teste de Tukey do acúmulo de glicina betaína ( $\mu \mathrm{mol} \mathrm{g}{ }^{-1}$ massa seca) de genótipos de guandu, IAC Fava Larga e Caqui, sob estresse salino $(\mathrm{NaCl})$ associado à adição exógena de espermidina (Spd), por 20 dias em solução nutritiva. Jaboticabal, SP. 2005-2006.

\begin{tabular}{lcc}
\hline $\begin{array}{l}\text { Causa } \\
\text { da Variação }\end{array}$ & G.L & $\begin{array}{c}\text { Quadrados Médios } \\
\text { Glicina betaína }\end{array}$ \\
\hline Genótipos (G) & 1 & $143,5676^{*}$ \\
Espermidina (Spd) & 1 & $360,3581^{* *}$ \\
Estresse salino (ES) & 3 & $1907,8005^{* *}$ \\
Interação (GxSpd) & 1 & $40,2003^{\mathrm{ns}}$ \\
Interação (GxES) & 3 & $552,1201^{* *}$ \\
Interação (SpdxES) & 3 & $144,0239^{* *}$ \\
Interação (GxSpdxES) & 3 & $121,3722^{* *}$ \\
Blocos & 4 & $68,0272^{*}$ \\
Resíduo & 60 & 26,7038 \\
C.V. (\%) & & 11,0833 \\
\hline Tratamentos & & Glicina betaína \\
\hline IAC Fava Larga & & $45,2850 \mathrm{~B}$ \\
Caqui & & $47,9643 \mathrm{~A}$ \\
Spd - 0,0 mM & & $48,7470 \mathrm{~A}$ \\
Spd - 0,5 mM & & $44,5023 \mathrm{~B}$ \\
DMS & & 2,3123 \\
\hline
\end{tabular}

Ns : não significativo $(\mathrm{P}>0,05) ;{ }^{* *}$ significativo a $1 \% \quad(\mathrm{P}<0,01)$; *significativo a $5 \%(\mathrm{P}<0,05)$; Médias seguidas de mesma letra não diferem entre si pelo teste de Tukey $(\mathrm{P}>0,05)$; C.V.: Coeficiente de Variação; DMS: Diferença Mínima Significativa.

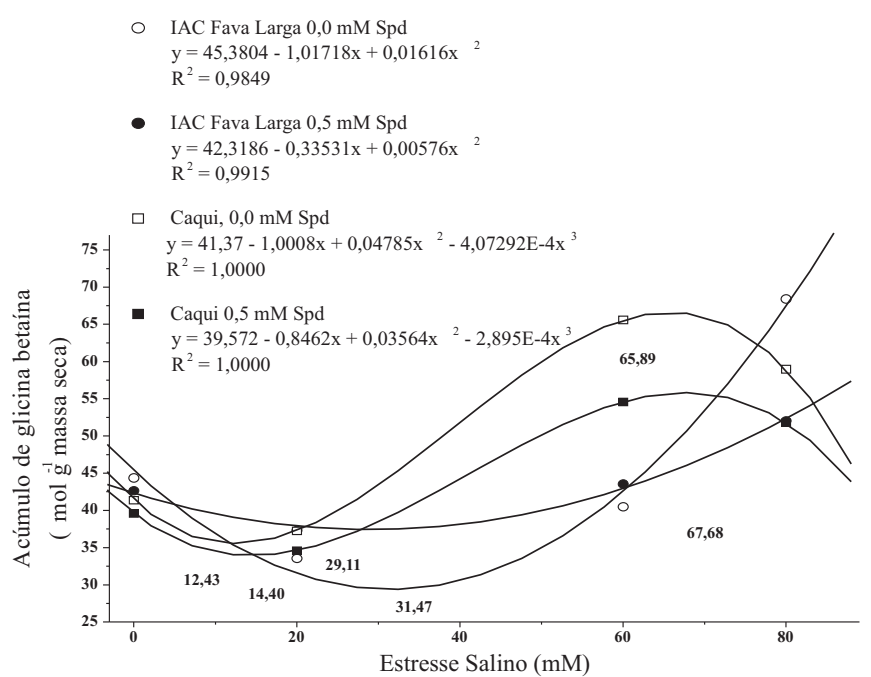

Figura 1. Acúmulo de glicina betaína ( $\mathrm{mmol} \mathrm{g}^{-1}$ massa seca) da parte aérea de genótipos de guandu, IAC Fava Larga e Caqui, sob estresse salino $(\mathrm{NaCl})$ associado à adição exógena de espermidina (Spd), por 20 dias em solução nutritiva. Jaboticabal, (SP), 2005-2006.
Com relação ao genótipo IAC Fava Larga, a tendência quadrática positiva a partir de $31,47 \mathrm{mM}$ de $\mathrm{NaCl}$ indica que ocorreu acúmulo de GB com o aumento das concentrações de $\mathrm{NaCl}$ (Figura 1). Tais resultados são compatíveis com os encontrados na literatura, na qual é relatada que a biossíntese de GB pode ser induzida, principalmente, sob condições de estresse salino (MunNs, 2002), podendo o teor desta substância variar, amplamente, entre as espécies, atingindo de $40 \mathrm{a} 400 \mu \mathrm{mol} \mathrm{g}^{-1}$ massa seca (SАКАмото e Murata, 2002). Entretanto, algumas espécies agronomicamente importantes (cenoura, feijão-soja, mamona, tabaco e mostarda) são incapazes de sintetizar este osmólito (CHA-UM et al., 2006). Ademais, o acúmulo de GB está restrito a um pequeno grupo de plantas cultivadas, tais como cevada, beterraba (GIBON et al., 1997) e espinafre (Sakamoto e Murata, 2002).

O tratamento com Spd exógena $(0,5 \mathrm{mM})$ causou efeitos distintos nos genótipos, com acúmulo de GB $\left(37,44 \mu \mathrm{mol} \mathrm{g}^{-1}\right.$ massa seca) a partir de 29,11 $\mathrm{mM}$ de $\mathrm{NaCl}$ no 'IAC Fava Larga' e acúmulo de GB $\left(33,91 \mu \mathrm{mol} \mathrm{g}{ }^{-1}\right.$ massa seca) no 'Caqui' a partir de $14,40 \mathrm{mM}$ de $\mathrm{NaCl}$ atingindo o máximo $(55,80 \mu \mathrm{mol}$ $\mathrm{g}^{-1}$ massa seca) em 67,68 mM de $\mathrm{NaCl}$ (Figura 1).

Em relação ao 'IAC Fava Larga', nota-se que a adição exógena de Spd induziu o acúmulo de GB sob menor nível de estresse salino $(29,11 \mathrm{mM})$, comparando-se com $0,0 \mathrm{mM}$ de Spd (31,47 mM). Em contrapartida, os resultados indicam que, não houve atenuação do estresse salino pela Spd devido à acentuada redução no acúmulo de GB nas concentrações de $80 \mathrm{mM}$ de $\mathrm{NaCl}$ para o 'IAC Fava Larga' e $60 \mathrm{mM}$ e $80 \mathrm{mM}$ de $\mathrm{NaCl}$ no 'Caqui' (Figura 1).

Na literatura pertinente, são escassos os estudos sobre o efeito da Spd exógena no acúmulo de GB nas plantas. No entanto, a biossíntese de GB está relacionada com a enzima betaína aldeído desidrogenase, BADH (SАКАмото е MuRATA, 2002), mas esta enzima também pode participar do catabolismo das poliaminas (Trossat et al., 1997). Deste modo, a redução no acúmulo de GB devido à adição exógena de Spd pode estar relacionada tanto na utilização da BADH na biossíntese de GB quanto no catabolismo da Spd.

Conclui-se assim, que a GB pode ser indicada como um marcador bioquímico-fisiológico do estresse salino para o 'IAC Fava Larga'.

\section{AGRADECIMENTO}

Os autores agradecem à Fundunesp, pelo financiamento do projeto (Proc. $n^{\circ} 00837 / 05$ ) e à Fapesp (Proc. $n^{\circ}$ 95/7177-3). 


\section{REFERÊNCIAS}

BANZATTO, D.A.; KRONKA, S.N. Experimentação agrícola. 4.ed. Jaboticabal: FUNEP, 2006. 237p.

CHA-UM, S.;SUPAIBULWATANA, K.; KIRDMANEE, C. Water relation, photosynthetic ability and growth of thai jasmine rice (Oryza sativa L. ssp. indica cv. KDML 105) to salt stress by application of exogenous glycinebetaine and choline. Journal Agronomy \& Crop Science, Berlin, v.192, p.25-36, 2006.

COSTA, N.L.; TOWNSEND, C.R.; MAGALHÃES, J.A.; PEREIRA, R.G.A. Formação e manejo de pastagens de guandu em Rondônia. RT/23, EMBRAPA-CPAF Rondônia. n.23, p.12, 2001. Disponível em: <www.cpafro.embrapa.br/Pesquisa/ public2001/past_forrag/RT_23.PDF> Acesso em 12 de dezembro de 2005.

FERRI, M.G.; ANDRADE, M.A.B.; LAMBERTI, A. Botânica: fisiologia, curso experimental. São Paulo: Melhoramentos/ Editora USP, 1974, 126p.

GIBON, Y.; BESSIERES, M.A.; LARHER, F. Is glycine betaine a non-compatible solute in higher plants that do not accumulate it? Plant, Cell and Environment, Oxford, v.20, p.329-340, 1997.

GONELA, A. Tolerância ao $\mathrm{NaCl}$ em variedades de Stylosantes guianensis (Aubl.) Sw. 1999. 128 f. Dissertação (Mestrado em Agronomia - Área de Genética e melhoramento de Plantas) Faculdade de Ciências Agrárias e Veterinárias - UNESP, Jaboticabal.

GRIEVE, C.M.; GRATTAN, S.R. Rapid assay for determination of water soluble quaternary ammonium compounds. Plant and Soil, The Hague, v.70, p.303-307, 1983.

MARTIN-TANGUY, J. Metabolism and function of polyamines in plants: recent development (new approaches). Plant Growth Regulation, Dordrecht, v.34, p.135-148, 2001.

MUNNS, R. Comparative physiology of salt and water stress. Plant, Cell and Environment, Oxford, v.25, p.239-250, 2002.

MUNNS, R. Genes and salt tolerance: bringing them together. New Phytologist, Cambridge, v. 167, p.645-663, 2005.

MUNNS, R. Approaches to increasing the salt tolerance of wheat and others cereals. Journal of Experimental Botany, Oxford, v.57, n.5, p.1025-1043, 2006.

NENE, Y.L.; HALL, S.D.; SHEILA, U.K. The pigeonpea. Cambridge: CAB, 1990. 490p.

SAKAMOTO, A.; MURATA, N. The role of glycine betaine in the protection of plants from stress: clues from transgenic plants. Plant, Cell and Environment, Oxford, v.25, p.163-171, 2002.

SALISBURY, F.B.; ROSS, C.W. Plant Physiology. Wadsworth Publishing, 1992. 682p.

SZABOLCS, I. Salt-afected soils. Flórida: Library of Congress, 1989. 274p.
TAIZ, L., ZEIGER, E. Fisiologia Vegetal. 3.ed. Trad. Eliane Romanato Santarém et al. Porto Alegre: Artmed, 2004. p. 618619.

TESTER, M.; DAVENPORT, R. $\mathrm{Na}^{+}$tolerance and $\mathrm{Na}^{+}$transport in higher plants. Annals of Botany, London, v.91, p.503-527, 2003.

TROSSAT, C.; RATHINASABAPATHI, B.; HANSON, A.D. Transgenically expressed betaine aldehyde dehydrogenase efficiently catalyzes oxidation of dimethylsulfoniopropionaldehyde and w-aminoaldehydes. Plant Physiology, Rockville, v.113, p.1457-1461, 1997.

VINCENT, J.M. A manual for the practical study of rootnodule bacteria. Oxford: Blackwell Scientific Publications, 1970. 200p. (IBP Hand book, 15) 